\title{
A Model of the Effect of Environmental Variables on the Presence of Otters along the Coastline of the Isle of Skye
}

\author{
Paul Yoxon \\ International Otter Survival Fund, Isle of Skye IV49 9DE, UK \\ Correspondence should be addressed to Paul Yoxon; paul@otter.org
}

Received 4 April 2013; Revised 15 July 2013; Accepted 16 July 2013

Academic Editor: Arianna Azzellino

Copyright ( 2013 Paul Yoxon. This is an open access article distributed under the Creative Commons Attribution License, which permits unrestricted use, distribution, and reproduction in any medium, provided the original work is properly cited.

\begin{abstract}
A survey of Eurasian otters (Lutra lutra) along the Skye coastline revealed a variation in distribution on different coastal types. Factors like geology, width of the intertidal zone, intertidal makeup, slope of coastline, inland vegetation, and number of freshwater pools could influence otter distribution. A quantitative method based on a logistic regression model is applied to take into account three scalable and four categorical environmental variables which may or may not affect otter distribution. Otter presence or absence in $500 \mathrm{~m}$ coastal sections was compared with binary dependent variables and a set of independent variables on 622 coastal sites. Analysis shows that this method can be used to characterise combinations of factors to predict if otters are likely to occur on a particular coastline. Geology, height $25 \mathrm{~m}$ above High Water Mark (indicating slope of coastline), and number of freshwater pools all affect otter utilisation of the coastal zone. Coastlines with Torridonian and Mesozoic rocks and the Landslip area show a positive effect on otters, while all other coastlines have a negative effect. Although primarily of theoretical importance, the model could be used as a tool to locate coastlines elsewhere which are of potential conservation importance for otters.
\end{abstract}

\section{Introduction}

The Isle of Skye is renowned for its geology, largely because of the huge variation in age and rock type (see Figure 1).

The oldest rocks are the Lewisian gneiss, which are up to 3,000 million years old and are in fact the oldest rocks in Britain. They are banded metamorphic rocks which have been altered by heat and pressure, and they form rugged, rocky coastlines. Lewisian rocks form much of the Sleat peninsula together with the Torridonian sandstone. The Torridonian is made of silica grains cemented together with silica which makes it impermeable, and so there are many freshwater pools. Cambrian rocks on Skye are mostly quartzite sandstones or limestones, although the limestones have been altered to form marbles as a result of the heat from Tertiary volcanic activity. Jurassic sediments, comprising mainly sandstones, limestones, and shales, form gently sloping shorelines. The youngest rocks are the Tertiary volcanics and intrusive. Volcanic rocks are those which are molten when they reach the earth's surface, but if they solidify within the earth, they are said to be intrusive. On Skye most of the volcanic rocks are in the north of the island and are basalts.
Minor intrusions are formed when magma is pushed through cracks in the country rock, and there are many intrusive dykes which sometimes appear like man-made walls. These can divide the shoreline providing sheltered pools where young otter cubs can learn to hunt or where animals can bring larger prey to shore to eat. Large masses of intrusive rocks are called major intrusions, and on Skye there are areas of acidic granite and basic gabbro. Both the volcanic and intrusive rocks are heavily fractured and are therefore porous, and so freshwater pools are not as common. The area of the landslip on the Trotternish peninsula is the most recent geological event and it continues today. Tertiary magma was intruded between the layers of Jurassic sediment to form a sill. This is a layer of weakness along which there is movement, and as the sea erodes the cliffline, the sediments slip forward. The resultant coastline has many fallen blocks under which otters can make their holt, but the actual bedrock forms a gently sloping coastline. For the purposes of this study the coastline of the island was divided into seven major geological zones as shown in Table 1.

It has been shown that on the Isle of Skye the geology of the coastal zone has an effect on the number of freshwater 


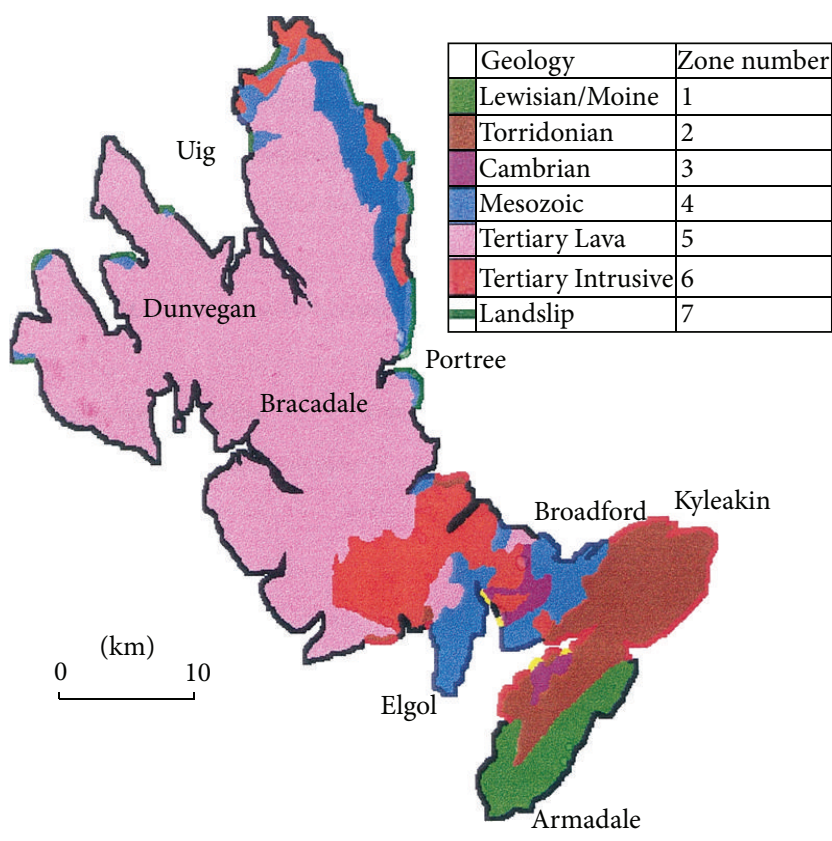

FIgURE 1: Geological coastal zones of the Isle of Skye.

pools, intertidal makeup, slope of the coastline, width of the tidal zone, and inland vegetation [2]. The intertidal makeup is related to the geology, but it is the variety of features found on the coastline as in cliffs, rocky shoreline, boulders, and sandy beaches. It has also been shown that although the diet, as shown by spraint analysis, is similar on all geological coastlines, the availability of prey from fish trapping was lower on the Tertiary Lava coastline. The distribution of otters is not even around the island: there are places where the population density was found to be quite high (e.g., Torridonian coastlines), while in other areas the density was lower (e.g., Tertiary Lava coastline). This paper will explore what factors may effect otter populations on each geological coastline by bringing together several environmental variables to try and predict the presence or absence of otters around the coastline.

In earlier studies in other areas, a variety of factors have been used to predict the presence or absence of otters. It was formerly thought that mink had a negative effect on otters, but otters are twice the size of mink, and it now seems that they out-compete with mink [3]. Mason [4] found that heavy metals and organochlorines correlate with the absence or decline of otters. However, in nonpolluted areas, as on the north west coastline of Scotland, other factors are important such as the presence of bankside vegetation $[5,6]$, water depth [7], peaty coastlines, and the presence of freshwater pools [8]. In Ireland [9] found that two habitat quality factors, namely, water pollution and bankside vegetation, had an effect on otter presence or absence. In Hungary, Kemenes and Demeter [10] looked at various environmental variables and found that depth of water and the density of bankside vegetation are the two factors which have the greatest influence on the occurrence of otters in particular sites, while in Slovakia otters were found in nearly all freshwater water bodies [11].
TABLE 1: Geological time scale. The seven zones used in this paper are shown in the column marked coastal zones. Ages for the geological periods are shown in millions of years and represent when the corresponding geological period begins. Data based on Eager and Dunning [1].

\begin{tabular}{|c|c|c|c|}
\hline $\begin{array}{l}\text { Years } \\
\text { (millions } \\
\text { of years) }\end{array}$ & Period & Epoch & $\begin{array}{l}\text { Coastal zones } \\
\text { (zone numbers) }\end{array}$ \\
\hline \multirow[t]{3}{*}{1.64} & Quaternary & & 7. Landslip \\
\hline & & Cainozoic & \\
\hline & & & $\begin{array}{l}\text { 6. Tertiary } \\
\text { Intrusives }\end{array}$ \\
\hline 65 & Tertiary & & 5. Tertiary Lavas \\
\hline 146 & Cretaceous & & \\
\hline 205 & Jurassic & Mesozoic & 4. Mesozoic \\
\hline 251 & Triassic & & \\
\hline 290 & Permian & & \\
\hline 353 & Carboniferous & Upper Palaeozoic & \\
\hline 395 & Devonian & & \\
\hline 439 & Silurian & & \\
\hline 510 & Ordovician & Lower Palaeozoic & \\
\hline 550 & Cambrian & & 3. Cambrian \\
\hline 3,000 & & Precambrian & $\begin{array}{c}\text { 2. Torridonian } \\
\text { 1. Lewisian/Moine }\end{array}$ \\
\hline
\end{tabular}

Food availability is a limiting factor for any species. The abundance of fish on all geological coastlines was looked at using nonbaited fish traps, and spraint analysis also revealed information on species availability. The main five prey species have been identified as viviparous blenny, butterfish, rockling, sea scorpion, and saithe which together make up $85 \%$ of the diet [2]. The diet analysed using spraint analysis showed all five species present, but the availability of fish using fish traps did differ with lower numbers of viviparous blenny, butterfish, and rockling in the Tertiary Lava zone $[2,12]$.

On Skye, the occurrence of otters is influenced by several characteristics of the habitat. In order to obtain a more realistic picture of the combined effect of a variety of environmental factors on the distribution of otters around the Skye coastline, a quantitative multivariate method was used. This looked at the variables and their relationships which might influence the occurrence of otters.

\section{Methods}

The Isle of Skye coastline was divided into 1,139 coastal sections of $500 \mathrm{~m}$, and of these 621 were surveyed, accounting for $55 \%$ of the total coastline.

The utilisation of a particular $500 \mathrm{~m}$ coastline by otters was ascertained using three methods:

(1) direct observation of otter activity,

(2) presence of holts, or

(3) a sprainting point. 
TABLE 2: Scalable variables recorded during the survey of the distribution of otters around the Skye coastline.

\begin{tabular}{ll}
\hline Parameter & Scale \\
\hline Width of tidal zone $(W)$ & $\begin{array}{l}\text { Maximum width of each } 500 \mathrm{~m} \\
\text { section } \\
\text { The height was recorded in the }\end{array}$ \\
Height 25 m above HWM $(H) \begin{array}{l}\text { centre of each } 500 \mathrm{~m} \text { section, } 25 \mathrm{~m} \\
\text { above High Water Mark. }\end{array}$ \\
$\begin{array}{l}\text { Number of freshwater pools } \\
(P)\end{array}$ & $\begin{array}{l}\text { Number of pools in each } 500 \mathrm{~m} \\
\text { section }\end{array}$ \\
\hline
\end{tabular}

Holt. Defined as a tunnel system with signs of regular use by otters $[8,13]$. The evidence of use consisted of tracks, flattened grass, fresh spraints, and the characteristic odour in the holt. On Skye, holts were found to be mainly in rock piles within $50 \mathrm{~m}$ of the shore, but they can also use holes in the ground. If two holts were more than $10 \mathrm{~m}$ apart, they were considered separately.

Spraint. Defined as the droppings of the otter which include the undigested hard parts of the prey. They are deposited mostly in conspicuous places and over time build up as green lumps due to the nitrophilous grasses which grow there.

A score of 1 was assigned if otters were found to utilise the $500 \mathrm{~m}$ section by any of the previous three criteria, and a score of 0 was assigned if no signs of otter were found. Statistical analysis was done using SPSS Version 6 for Windows.

\subsection{The Variables Used in the Study}

2.1.1. Scalable Variables. At each $500 \mathrm{~m}$ section, three scalable and four categorical variables were recorded. The scalable variables are shown in Table 2.

A freshwater pool was defined as an area of standing water with a minimum width or length of $0.5 \mathrm{~m}$ and minimum depth of $0.1 \mathrm{~m}$. It was found from personal observation that otters show no signs of utilising pools with dimensions less than this.

2.1.2. Categorical Variables. In logistic regression, the codes of the independent variables must be meaningful [14]. It is not valid to take a nominal variable such as vegetation, assign an arbitrary code from 1 to 5 , and then use the resulting variable in the model. For this reason, the four categorical variables were recoded to create a new set of variables that correspond in some way to the original categories. Using this method, the new coded variables can then be compared; for example, scrub vegetation can be compared with the average effect of all other vegetation types on the presence of otters. The categorical variables are shown in Table 3.

In this model, I wanted to compare the effect of each category to the average effect of all categories, and so the deviation default coding and the coefficients of the new variables created were used to represent the effect of the new variable on the average effect of all the other categories [14]. With this coding system, the logistic regression coefficients show how much better or worse each category is compared
TABLE 3: Categorical variables recorded during the survey of the distribution of otters on the Isle of Skye.

\begin{tabular}{ll}
\hline Parameter & Category \\
\hline & $1=$ Lewisian/Moine \\
& $2=$ Torridonian \\
& $3=$ Cambrian \\
& $4=$ Mesozoic \\
& $5=$ Tertiary Lavas \\
Geology $(G)$ & $6=$ Tertiary Intrusive \\
& $7=$ Landslip \\
\hline The dominant boulder size in each $500 \mathrm{~m}$ & $1>20$ cm \\
section & $2<20$ cm \\
\hline & $1=$ muddy \\
& $2=$ sandy \\
Intertidal makeup (I) & $3=$ shingle \\
& $4=$ boulder \\
& $5=$ rock outcrop \\
\hline Inland vegetation $(V)$ & $1=$ heather \\
& $2=$ scrub \\
& $3=$ grassland \\
& $4=$ native wood \\
& $5=$ plantation \\
\hline
\end{tabular}

to the average effect of all the categories. The number of new variables required to represent a categorical variable will be one less than the number of categories. The coefficients of a categorical variable are relative, and the results for geology and vegetation should both be used rather than just one in isolation.

2.2. Model. Logistic regression analysis uses presenceabsence data on the dependent variables (otter utilisation) to produce a regression model. This gives the probability of the occurrence of otters on a $500 \mathrm{~m}$ section of coast given particular values of independent variables (environmental attributes). A detailed account of the technique is given in [14].

The model can be written in terms of the probability of otters being present (the ratio of the probability that they will occur to the probability that they will not).

Consider

$$
\frac{\text { Prob (otter) }}{\text { Prob (no otter) }}=e^{B_{0}+B_{1} X_{1} \cdots B_{s} X_{s}},
$$

where $B_{1}$ and $B_{s}$ are coefficients estimated from the data, $X$ is the independent variable, and $e$ is base of the natural logarithms.

Then $e$ raised to the power $B_{i}$ is the factor by which the odds change when the $i$ th independent variable increases by one unit. If $B_{i}$ is positive, this factor will be greater than 1 and the odds are therefore increased. If $B_{i}$ is negative, the factor will be less than 1 , which means that the odds are decreased. When $B_{i}$ is 0 , the factor will be equal to 1 , which leaves the odds unchanged. 
For several independent variables, the model can be written as follows:

$$
\text { Probability of otter utilising section (Prob O) }=\frac{1}{\left(1+e^{-z}\right)} \text {, }
$$

where $e$ is base of natural logarithms and $z$ is linear combination of the environmental attributes, and can be written as $z=B_{0}+B_{1} X_{1}+B_{2} X_{2} \cdots B_{s} X_{s}$.

A plot of logistic regression curve for $z$ values between 5 and -5 is S-shaped. The relationship between the independent variables and the probability is nonlinear, and the probability estimates will always be between 0 and 1 , regardless of the value of $z$. If the estimated probability of an otter occurring was less than 0.5 , it could be predicted that otters would not be present, and if the probability was greater than 0.5 , it could be predicted that otters would be present.

Backward stepwise regression was used for this model. In this, all the variables are first entered in to the model in a single step. The variables are then examined to look at their effect on presence or absence of otters and then removed one by one. Once no more variables meet the removal criteria, or when the model is identical to the previous one, the algorithm stops.

Many ways exist to see if the model fits the data. In this study I used classification tables to compare my predictions to the observed outcomes and a graph to see the distribution of the predicted probabilities (Table 4, Figure 2).

\section{Results}

Table 4 shows the parameter estimates for the logistic regression model for backward stepwise regression based on the available data.

Although the geology of the coastal section showed a relationship to height and pools [2], it was included in this calculation, so that a full comparison in the logistic regression model could be made. Significant results were obtained for the variables Geology (Lewisian, (Geology 1), Torridonian (Geology 2), Tertiary Lavas (Geology 5)) and also for freshwater pools and height. The coefficient for the Landslip (Geology 7), which is not displayed in Table 4, is no longer 0 but the negative of the sum of the displayed coefficients which is

$$
-(-1.093+0.982-0.204+0.473-0.611-0.405)=0.85 \text {. }
$$

The linear combination of environmental variables can be written as follows:

$$
\begin{aligned}
z= & 2.9(P)-0.013(H)-1.09(\text { Lewisian }) \\
& +0.98(\text { Torridonian })-0.61(\text { Tertiary Lava }) \\
& +0.85(\text { Landslip })-0.3064
\end{aligned}
$$

where $H$ is height and $P$ is freshwater pools.

If the geology was omitted from the calculation, the equation would be written as follows:

$$
z=2.9(P)-0.014(H)-0.47 \text {. }
$$

The positive logistic regression coefficient $(B)$ values in Table 4 indicates that having more Torridonian (Geology 2) and Landslip (Geology 7) coastlines would increase the probability of finding otters, and increasing the number of freshwater pools would also have a positive effect on finding otters. A negative logistic regression coefficient (B) of the height marker the Lewisian (Geology 1), and Tertiary Lava (Geology 5), indicates that increasing the slope of the shoreline and having more of these geological coastal types would have a negative effect on finding otters. The values for the geology are only relative, and Table 4 for geology shows that the Lewisian (Geology 1) has a negative effect on finding otters compared with the average effect of all the other variables.

The degree to which a unit change in these independent variables changes the odds of finding otters is not equal: the odds of finding otters are much more resistant to a unit change in the number of pools $(\operatorname{Exp}(B)=18.2)$ than any other variables.

The other variables investigated are not in the equation and are shown in Table 5, because these logistic regression coefficients were not significantly different from 0 . They can therefore be expected to have only a small effect on the probability of finding otters.

\subsection{Diagnostics}

3.1.1. Testing the Goodness Fit of the Model. The classification Table 6 shows that 257 sites without otters were predicted correctly by the model not to have otters; similarly at 251 sites where the model predicted the positive presence of otters, signs were indeed found. However, at 34 sites, the model predicted the presence of otters, but no signs were found, and at 79 sites where the model predicted no otters, signs were found. Therefore $88.3 \%$ of the survey sites without otters were predicted by the model not to have otters, whereas $76.1 \%$ of sites where signs of otters were found were predicted to have otters by the model. Therefore the model overall predicted accurately the presence or absence of otters in over $81 \%$ of all cases.

The table does not, however, reveal the distribution of the estimated probabilities of where otters are and are not found. Table 6 only shows whether or not the estimated probability is greater than 0.5 .

Figure 2 shows the efficiency of estimating the probability of finding and not finding otters. If our model successfully distinguishes the two groups, the cases for which an event has occurred (i.e., signs of otters have been found (1)) should be to the right of 0.5 , while those cases which have not had the event (i.e. no signs of otters have been found (0)), should be to the left of 0.5 . The more the groups cluster at their respective end the better the model is. This was indeed the case for the majority of cases, and Figure 2 shows that the model is slightly better at predicting the absence of otters than the presence with no predicted probabilities of not finding otters above 0.6 but one case with estimated probabilities of finding otters below 0.25 . Upon examination of the 100 cases close to the 
TABLE 4: Results of backward stepwise regression model.

\begin{tabular}{lccccccc}
\hline Variable & $B$ & SE & Wald & df & Sig & $R$ & 0.18 \\
\hline Geology & & & 38.51 & 6 & 0.00 & $\operatorname{Exp}(R)$ \\
Geology(1) & -1.09 & 0.31 & 12.04 & 1 & 0.00 & -0.11 & 0.34 \\
Geology(2) & 0.98 & 0.33 & 8.64 & 1 & 0.00 & 0.09 & 2.67 \\
Geology(3) & -0.20 & 0.52 & 0.15 & 1 & 0.69 & 0.00 & 0.82 \\
Geology(4) & 0.47 & 0.25 & 3.53 & 1 & 0.06 & 0.04 & 1.60 \\
Geology(5) & -0.61 & 0.21 & 8.74 & 1 & 0.00 & -0.89 & 0.54 \\
Geology(6) & -0.41 & 0.25 & 2.59 & 1 & 0.11 & -0.03 & 0.06 \\
Height & -0.01 & 0.01 & 5.24 & 1 & 0.02 & 0.00 \\
Pools & 2.90 & 0.33 & 76.11 & 1 & 0.00 & 0.29 \\
Constant & -0.31 & 0.17 & 3.22 & 1 & 0.07 & 18.24 \\
\hline
\end{tabular}

Geology(1): Lewisianl; Geology(2): Torridonian; GEOLOGY(3): Cambrian; Geology(4): Mesozoic; Geology(5): Tertiary Lava; Geology(6): Tertiary Intrusive. Height: height $25 \mathrm{~m}$ from High Water Mark.

Pools: number of freshwater pools.

$B$ : logistic regression coefficient.

SE: standard error of the logistic regression coefficient.

Sig: significance of Wald statistic. (The Wald statistic has a chi-square distribution. When a variable has a single degree of freedom, the Wald statistic is the square of the ratio of the coefficient to its standard error).

$R$ : partial correlation coefficient of the individual variable.

$\operatorname{Exp}(R)$ : factor by which the odds of finding otters change when the individual unit increases by one unit.

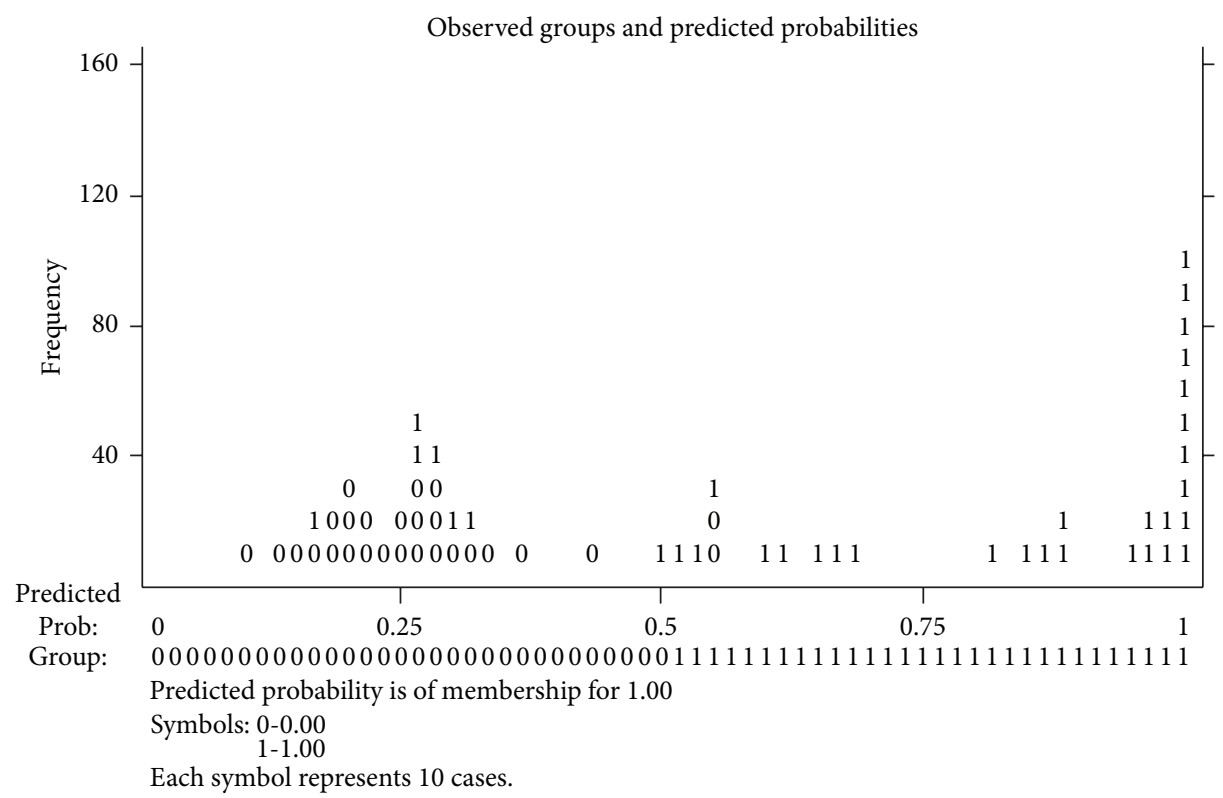

FIGURE 2: Histogram of estimated probabilities of finding and not finding otters. Frequency shows the number of cases $(1=$ finding otters; 0 $=$ not finding otters).

probability of one which predict the presence of otters, 60 of these come from the Torridonian sandstone coastal zone.

\section{Discussion}

There are several factors which influence the presence or absence of any species: food availability, habitat suitability, pollution, human disturbance, and possible predators, and these should all be taken into account when attempting to create a model to predict presence/absence.
As mentioned the fish availability as identified by nonbaited fish traps appeared to have lower numbers of viviparous blenny, butterfish, and rockling in the Tertiary Lava zone. However, when the spraint was analysed, all five main prey species were found to be present, and therefore food availability does not appear to be important here.

Adult otters have few predators, although cases of predation by orca whales have been recorded on Shetland, and grey seals have been reported to attack. Dogs can be a problem but only on a small scale, so the issue of predation is not a limiting factor. 
TABLE 5: Variables not in the backward stepwise regression model.

\begin{tabular}{lcccc}
\hline Variable & Score & df & Sig & $R$ \\
\hline Boulder & 0.81 & 1 & 0.37 & 0.00 \\
Coast & 5.35 & 4 & 0.25 & 0.00 \\
$\quad$ Coast(1) & 0.04 & 1 & 0.83 & 0.00 \\
Coast(2) & 0.71 & 1 & 0.40 & 0.00 \\
Coast(3) & 0.00 & 1 & 0.90 & 0.00 \\
$\quad$ Coast(4) & 0.76 & 1 & 0.38 & 0.00 \\
Veg & 2.23 & 4 & 0.69 & 0.00 \\
Veg(1) & 0.51 & 1 & 0.47 & 0.00 \\
$\quad$ Veg(2) & 0.24 & 1 & 0.63 & 0.00 \\
$\quad$ Veg(3) & 0.82 & 1 & 0.37 & 0.00 \\
Veg(4) & 0.51 & 1 & 0.47 & 0.00 \\
Width & 0.01 & 1 & 0.90 & 0.00 \\
\hline
\end{tabular}

Boulder: boulder size; Coast(1): mud; Coast(2): sandy; Coast(3): silty; Coast(4): boulder. VEG(1): heather; $\operatorname{Veg}(2)$ : scrub; Veg(3): grassland, Veg(4): native woodland.

Sig: significance of Wald statistic.

$R$ : partial correlation coefficient of the individual variable.

TABLE 6: Classification table for the goodness fit of the logistic regression model on the otter survey data on Skye.

\begin{tabular}{lccc}
\hline \multirow{2}{*}{ Observed } & \multicolumn{2}{c}{ Predicted } & Percentage correct \\
\hline 0 & 0 & 1 & $88.32 \%$ \\
1 & 257 & 251 & $76.06 \%$ \\
& 79 & Overall $81.80 \%$ & \\
\hline
\end{tabular}

$0=$ no otters, $1=$ otters present.

The Isle of Skye has a population of about 10,500 people, and most of this population is concentrated in the major villages on the island. But even here otters are seen on the shore in the village, right in front of houses, at ferry terminals, and so forth. Therefore it can be assumed that the level of human disturbance is minimal here. Otters are also known to live in the area of the huge oil terminal at Sullom Voe, Shetland. However, in very busy areas human disturbance could be a determining factor.

Otters are very strong swimmers, and it would appear that they are unaffected by stormy conditions. Indeed they are regularly seen feeding in extreme gales on the west coast of the Scottish islands, which are extremely exposed to such conditions. So it can be concluded that any effects of a shoreline being on the windward or lee side are minimal.

The number of freshwater pools and the geology of the coastal zone are the two factors (out of the seven scalable and categorical variables considered in this study), which have the greatest influence on the presence or absence of otters on Skye. The importance of the availability of freshwater pools has been demonstrated in previous studies in Shetland [15], South Africa, [16], and Skye [2, 12, 17]. However, the confirmation that geology has an effect on the distribution of otters is a new finding with Torridonian coastlines and Landslip coastlines the most favoured, as shown by the multiple regression model.
Another interesting prediction from the analysis is that the inland vegetation, intertidal makeup, width of the tidal zone, and size of the boulders on the coastline have no, or very little, effect on the occurrence of otters along the coastline. The fact that inland vegetation does not seem to have an effect on otters on Skye is interesting as in many other studies $[5,10,18]$ the bankside vegetation on river systems was one of the most important variables that had an influence on otter utilisation. It appears that if we look at the degree of unit change in the number of freshwater pools or the length of Torridonian coastline and the slope of the coastline, we see that the first two variables, and especially the number of freshwater pools, have a much more profound effect on finding otters. This means that otter populations are extremely sensitive to a reduction in the number of freshwater pools along the coastline. From a practical conservation point of view, it is essential to preserve or even create more freshwater pools along a coastline in order to sustain the otter population.

Considering the predictive value of the model, it can be concluded that this model was accurate at predicting the presence or absence of otters around the Skye coastline in over $81 \%$ of cases. The estimated probability plots revealed that the model is slightly better at predicting the absence of otters than the presence as shown in Figure 2 with one estimated probability of finding otters below 0.25 .

In 2006, we undertook an otter survey of Applecross in order to test if the model could be applied to other coastal areas. In Applecross the coastline also consists of Torridonian sandstone this would suggest that there should be a high density of otter variables, and this was indeed the case. Over the course of the survey we covered a total of $27.7 \mathrm{~km}$ of coastline, and we also had good sightings of otters including a mother and cubs. We found 39 holts, 381 sprainting points, and 53 freshwater pools. On average that is one holt per $0.71 \mathrm{~km}$ of coastline compared with one holt per $1 \mathrm{~km}$ on the Torridonian Skye coastline [2].

Therefore it can be concluded that the logistic regression analysis is a useful tool in assessing the effect of the different variables and for finding which of these variables have a positive effect on finding otters around the Skye coastline. It is becoming increasingly important in conservation to predict the occurrence of otters by habitat characteristics alone [19] as an alternative to long field surveys. This method will, therefore, help otter conservation in other areas by identifying coastlines with an optimum set of environmental variables, which can then be explored in greater detail, and the suitability of otter habitats is established.

\section{References}

[1] R. M. Eager and F. W. Dunning, The Chief Divisions of Geological Time, British Geological Survey, Nottingham, UK, 1992.

[2] P. Yoxon, The effect of geology on the distribution of the Eurasian otter (Lutra lutra) on the Isle of Skye [Ph.D. thesis], Open University, Milton Keynes, UK, 1999.

[3] L. Bonesi, R. Strachan, and D. W. Macdonald, "Why are there fewer signs of mink in England? Considering multiple 
hypotheses," Biological Conservation, vol. 130, no. 2, pp. 268$277,2006$.

[4] C. F. Mason, “The significance of PCB's in otters in national and regional scales," IUCN Otter Specalist Group Bulletin, vol. 14, pp. 3-12, 1997.

[5] C. F. Mason and S. M. Macdonald, Otter Ecology and Conservation, Cambridge University Press, Cambridge, UK, 1986.

[6] M. B. Aued, C. Chéhebar, G. Porro, D. W. Macdonald, and M. H. Cassini, "Environmental correlates of the distribution of southern river otters Lontra provocax at different ecological scales," ORYX, vol. 37, no. 4, pp. 413-421, 2003.

[7] U. Glimmerveen and E. J. Ouwerkerk, Habitat Use of Marine Otters: An Analysis of Otter Activity and Relation to Environmental Factors in a Coastal Area in Shetland, Institute of Terrestrial Ecology, Banchory, Scotland, 1984.

[8] H. Kruuk, A. Moorhouse, J. W. H. Conroy, L. Durbin, and S. Frears, "An estimate of numbers and habitat preferences of otters Lutra lutra in Shetland, UK," Biological Conservation, vol. 49, no. 4, pp. 241-254, 1989.

[9] R. M. Lunnon and J. D. Reynolds, "Distrobution of the Otter (Lutra lutra) in Ireland and its value as an indicator of habitat quality," in Bio-Indicators and Environmental Managemant, Academic Press, London, UK, 1991.

[10] I. Kemenes and A. Demeter, "A predictive model of the effect of environmental factors on the occurrence of otters (Lutra lutra) in Hungary," Hystrix, vol. 7, pp. 209-218, 1995.

[11] P. Urban, "The Eurasian Otter (Lutra lutra) in Slovakia-a preliminary report from a survey," IUCN/SCC Otter Specialist Group Bulletin, vol. 27, no. 3, pp. 147-157, 2010.

[12] P. Yoxon, "Otter surveys of the North West Scottish Islands," Scholarly Research Exchange, vol. 2008, Article ID 735403, 10 pages, 2008.

[13] G. Liles, Otter Breeding Sites, Conservation and Management. Conserving Natura 2000 Rivers conservation techniques Series No. 5, English Nautre, Peterboroungh, UK, 2003.

[14] M. J. Norusis, SPSS Advanced Statistics 6.1, SPSS, Chicago, Ill, USA, 1994.

[15] H. Kruuk and D. Balharry, "Effects of sea water on thermal insulation of the otter, Lutra lutra," Journal of Zoology, vol. 220, no. 3, pp. 405-415, 1990.

[16] D. Van der Zee, "Prey of the cape clawless Otter (Aonyx capensis) in the Tsitsikama Coastal National Park, South Africa," Journal of the Zoological Society of London, vol. 194, pp. 467-483, 1981.

[17] L. Lovett, H. Kruuk, and X. Lambin, "Factors influencing use of freshwater pools by otters, Lutra lutra, in a marine environment," Journal of Zoology, vol. 243, no. 4, pp. 825-831, 1997.

[18] D. G. Georgiev, "Habitats of the otter (Lutra lutra L.) in some regions of Southern Bulgaria," IUCN/SCC Otter Specialist Group Bulletin, vol. 22, no. 1, pp. 6-13, 2005.

[19] L. J. Dubuc, W. B. Krohn, and R. B. Owen Jr., "Predicting occurrence of river otters by habitat on Mount Desert Island, Maine," Journal of Wildlife Management, vol. 54, no. 4, pp. 594599, 1990. 

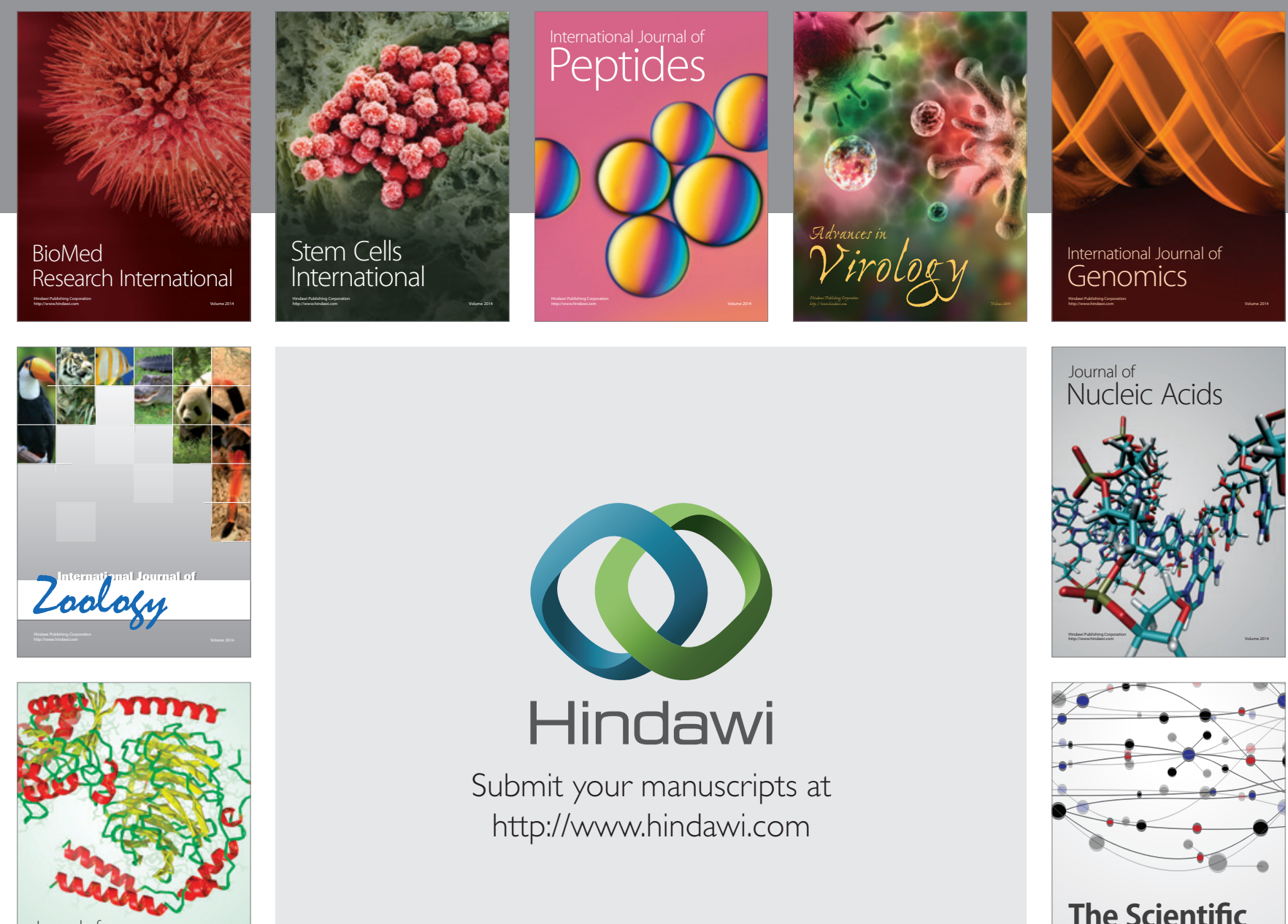

Submit your manuscripts at

http://www.hindawi.com

Journal of
Signal Transduction
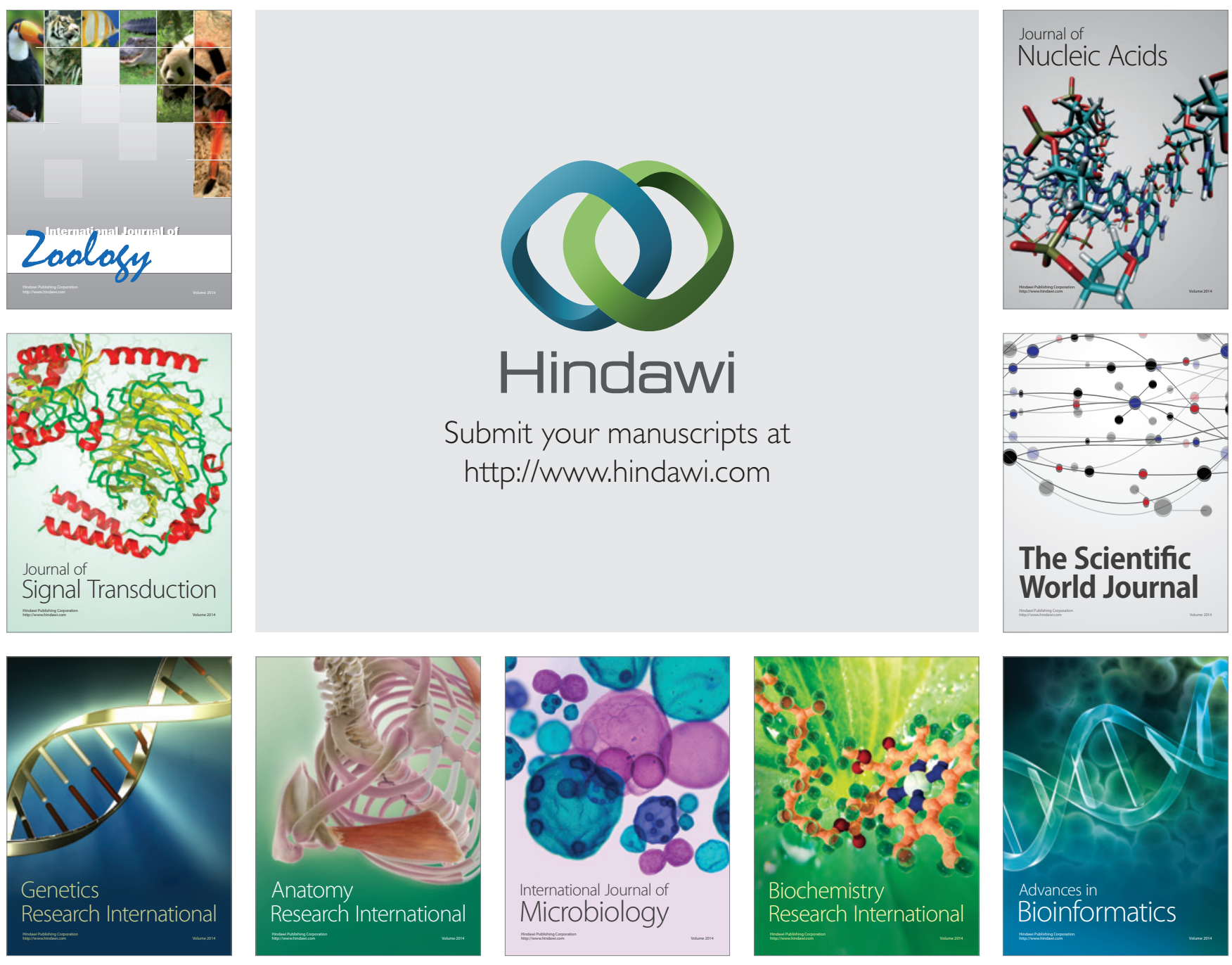

The Scientific World Journal
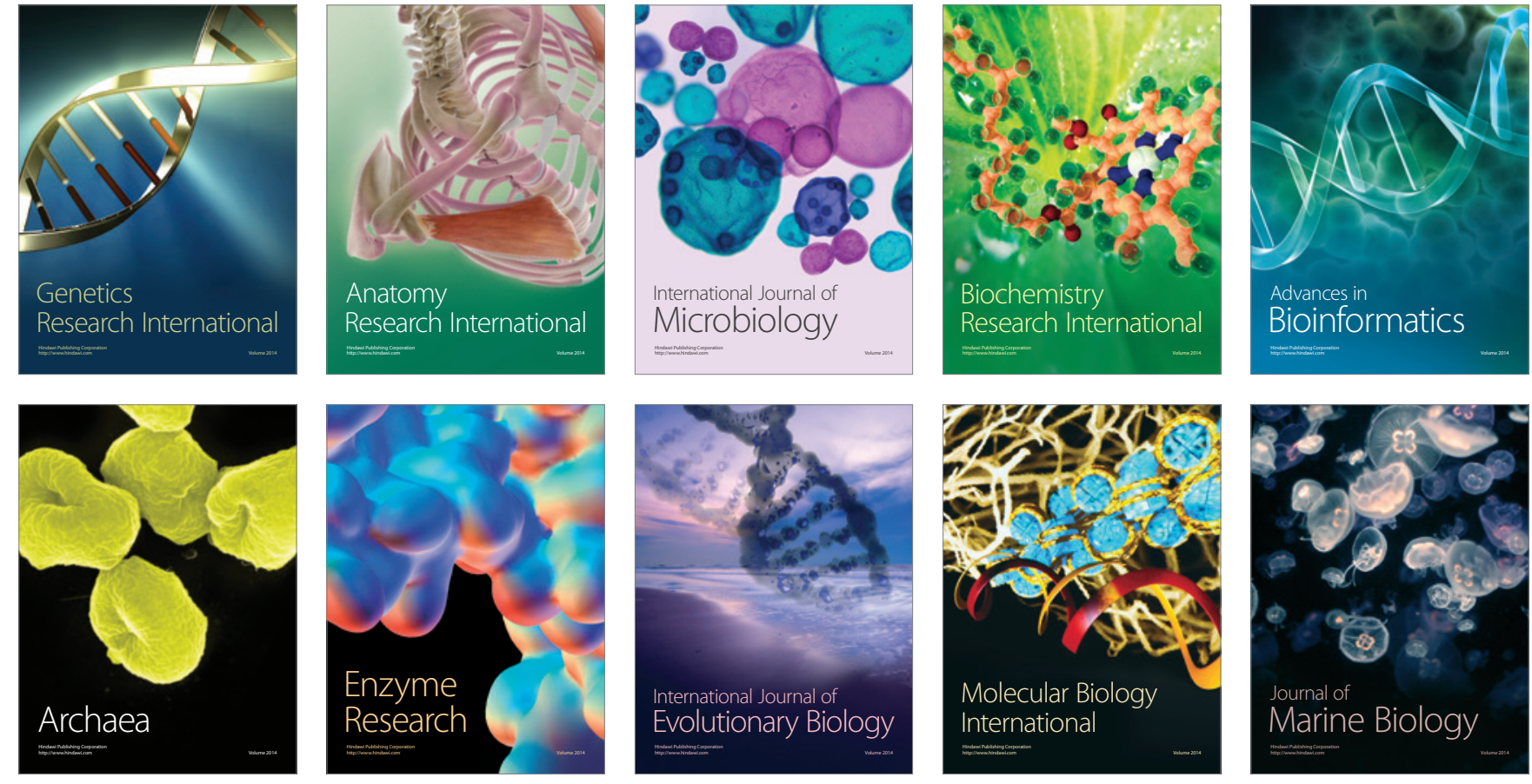